OPEN ACCESS

Edited by:

Haibo Yang,

Tianjin Normal University, China

Reviewed by:

Jill Leslie Littrell,

Georgia State University,

United States

Priya Alat,

Rajagiri Business School, India

*Correspondence: Michael Belz

michael.belz@med.unigoettingen.de

Specialty section:

This article was submitted to

Public Mental Health,

a section of the journal

Frontiers in Sociology

Received: 06 May 2021 Accepted: 06 September 2021 Published: 15 September 2021

Citation:

Misamer M, Signerski-Krieger J, Bartels C and Belz M (2021) Internal Locus of Control and Sense of Coherence Decrease During the COVID-19 Pandemic: A Survey of

Students and Professionals in

Social Work

Front. Sociol. 6:705809.

doi: 10.3389/fsoc.2021.705809

\section{Internal Locus of Control and Sense of Coherence Decrease During the COVID-19 Pandemic: A Survey of Students and Professionals in Social Work}

\author{
Melanie Misamer ${ }^{1}$, Jörg Signerski-Krieger ${ }^{2}$, Claudia Bartels ${ }^{2}$ and Michael Belz ${ }^{2 *}$ \\ ${ }^{1}$ HAWK University of Applied Sciences and Arts, Göttingen, Germany, ${ }^{2}$ Department of Psychiatry and Psychotherapy, University \\ Medical Center, Göttingen, Germany
}

Mental health is severely challenged by the COVID-19 pandemic due to a variety of restrictions in public and private life. Students in particular may face additional and unique stressors: face-to-face classes have been largely replaced by digital formats, leading to further reduced social contacts, thus facilitating the development of psychological symptoms. In this study, we aimed to assess the impact of the current peri-pandemic situation on students' 1) locus of control and 2) sense of coherence, both of which have been linked to mental health in previous work. A total of 403 social work students from Germany participated, providing both retrospective (pre-pandemic) and current (February/ March 2021) ratings. Furthermore, 324 social work professionals were included to analyze differences between both groups. Locus of control shifted significantly from internal to external during the pandemic for students and professionals. Furthermore, high mental burden correlated with increased external and decreased internal locus of control. Sense of coherence decreased during the pandemic for the entire sample and correlated with high mental burden. Overall, students showed a stronger drop compared to professionals, primarily due to a more pronounced decrease in perceived meaningfulness (all $p<0.001$ ). In summary, students and professionals responded with increased feelings of powerlessness in the absence of sufficient coping strategies - this could lead to further deterioration of mental health as the pandemic continues. In this context, students appear to be particularly vulnerable to a reduction in sense of coherence. We conclude that interventions to improve coping strategies are urgently needed.

Keywords: mental health, locus of control, sense of coherence, feeling of powerlessness, coping strategies

\section{INTRODUCTION}

The COVID-19 pandemic has led to significant changes in public and private life, in part due to extensive restrictions during multiple lockdowns (Castiglioni and Gaj, 2020). These restrictions have severely challenged mental health in general (e.g., Kesner and Horáček, 2020). Because individual resources (in particular: social contacts) may subsequently be lost due to pandemicrelated restrictions, individuals may become increasingly vulnerable to "spirals of loss" (Hobfoll, 2001), finally leading to an increased stress response. Accordingly, numerous studies point to a 
potential increase in mental disorders as a result of the pandemic, both for the general population (Wang et al., 2020; Rossi et al., 2020), and for health care workers (Tan et al., 2020; Kramer et al., 2021). The pandemic may also negatively impact general well-being (Jung et al., 2020), psychological resilience, and stress levels (McGinty et al., 2020).

The need for control is widely considered as a central human need (Grawe, 1998). Subjective loss of control during the pandemic, as a reaction to extensive restrictions and the unpredictability of the pandemic's dynamics, has negative consequences on mental health, and also increases general stress levels and mental health problems (Kinman et al., 2020; Usher et al., 2020). In this regard, the psychological concept of locus of control represents a pertinent framework to operationalize the loss of control during the COVID-19 pandemic. It describes the extent to which individuals are convinced that they can control events themselves as a consequence of their own behavior (internal locus of control, in other words: gain of control), or feel powerless or controlled by external factors (external locus of control, in other words: loss of control) (Rotter, 1966). Over the past decades, a variety of studies have demonstrated a relationship between high internal locus of control and both mental and physical health (e.g., Jain and Singh, 2015; Kesavayuth et al., 2020). In the context of the COVID-19 pandemic, restrictive measures enacted by governmental authorities potentially shift feelings of locus of control from the internal to the external domain, and may result in negative consequences for mental health (Sigurvinsdottir et al., 2020; Alat et al., 2021).

Besides subjective loss of control, the individual ability to cope with the effects of the COVID-19 pandemic has been reported to have a major influence on mental health (Baloran, 2020). Routine coping mechanisms may prove useless during the pandemic and subsequently may lead to mental health problems (Barni et al., 2020). In this matter, the concept of sense of coherence (SOC) describes the individual ability to employ coping strategies to overcome a negative experience (Antonovsky, 1979). A prerequisite for successful coping is the perceived manageability of a situation, as well as its meaningfulness and the ability to understand the experience (comprehensibility). A pronounced sense of coherence has been associated with mental health and quality of life in numerous studies (e.g., Länsimies et al., 2017; Schäfer et al., 2018; del-Pino-Casado et al., 2019). Despite all efforts, individuals potentially perceive the pandemic and associated changes in daily life as being a great challenge to cope with. In this matter, pandemic-related restrictions may not always be perceived as being meaningful and/or completely understandable from the individual point of view. In this light, recent studies suggest that-apart from perceived locus of control-there is a negative relationship between sense of coherence and the COVID-19 pandemic. As a result, psychological stress levels may increase and mental health may deteriorate significantly (Gómez-Salgado et al., 2020; Schäfer et al., 2020; Leung et al., 2021; Ruiz-Frutos et al., 2021).
Young people and students in particular may face unique stressors during the course of the pandemic, as several empirical studies have shown. In general, face-to-face teaching has been widely replaced by digital teaching-this usually results in an additional reduction of social contacts and exchange opportunities for students (Chaturvedi et al., 2021). Most studies noted an increase of psychological symptoms in the context of the pandemic and frequently reported increased stress, anxiety, and/or depressive symptoms (e.g., Wang et al., 2020; Son et al., 2020; Meda et al., 2021). Elmer et al. (Elmer et al., 2020) suggested that COVID-19-specific concerns (including concerns about isolation, limited social networks, family health) may substantially contribute to these findings. Furthermore, there is evidence of increased anxiety about the future and lower well-being, particularly among undergraduate students (Dodd et al., 2021). In addition, online teaching potentially leads to a higher time burden for students and thus acts as an additional stressor (Dost et al., 2020).

Irrespective of the COVID-19 pandemic, it has also been shown for students that a pronounced internal locus of control is generally associated with better mental health (e.g., Sidola et al., 2015; Kurtović et al., 2018). However, studies on the specific influence of the COVID-19 pandemic on the perceived locus of control in students are not yet available. For sense of coherence, one previous study in nursing students has shown that it has been significantly less pronounced during the pandemic (Reverté-Villarroya et al., 2021).

According to the empirical results so far, it is to be expected that students react to pandemic-related restrictions with pronounced feelings of powerlessness in the sense of 1) a reduced internal locus of control and 2) a reduced sense of coherence (and subsequently with mental burden). However, studies assessing the extent to which students are vulnerable in the context of the pandemic are scarce. The present crosssectional survey aims to fill this research gap. The following hypotheses are empirically tested based on data from 403 social work students. The aim is to examine differences between retrospectively assessed (before the COVID-19 pandemic) and current experiences (approximately 1 year after the pandemic began, i.e., February/March 2021), with respect to locus of control and sense of coherence:

H1a: Students' internal locus of control was higher before the COVID-19 pandemic than during the pandemic (February/ March 2021).

$H 1 b$ : Students' external locus of control was lower before the COVID-19 pandemic than during the pandemic (February/ March 2021).

H2: Students' sense of coherence in students was higher before the COVID-19 pandemic than during the pandemic (February/March 2021).

Since there is only insufficient evidence on pandemic-related vulnerability among students in comparison to professionals to date, this study also surveyed 324 social work professionals for all primary endpoints to uncover possible differences between both groups. 


\section{METHODS}

\section{Sample and Study Design}

A Germany-wide cross-sectional online questionnaire study was conducted with social work students and professionals from February 17 to March 7, 2021, via the SoSci platform (SoSci Survey $\mathrm{GmbH}$ ). The aim of the survey was to capture both the 1) current ratings on the selected scales on locus of control and sense of coherence during the COVID-19 pandemic (February/ March 2021) and the 2) retrospective assessment of the participants before the COVID-19 pandemic (see Measurement for details). The use of retrospective measures is a well-established method (Suar et al., 2015). Especially during the COVID-19 pandemic which makes it difficult to conduct prospective studies it is a useful and feasible approach to assess pandemic-related changes (Bäuerle et al., 2020; Van Rheenen et al., 2020; Belz et al., 2021; Robillard et al., 2021). From March 8, 2021, the so-called nationwide "second lockdown" ended in Germany and was followed by easing of pandemic-related restrictions (Federal Government Germany, 2021). The survey was stopped from that date to avoid systematic bias.

Acquisition of online questionnaires was carried out nationwide via three routes: 1) social networks and platforms (e.g., Facebook, XING, or Telegram): Closed online groups and communities consisting of members from the field of social work were selected for acquisition (e.g., "Social Work," "Critical Social Work", and especially student groups from universities). 2) Universities in Germany: E-mail distribution lists for social work students at the University of Applied Sciences and Arts (HAWK) in Göttingen, Hildesheim and Apollon University in Bremen were used. 3) Social work institutions: Specific areas represented by social workers were contacted by e-mail (e.g., residential group areas of the AWO or youth welfare of the Diakonie).

In sum, 881 persons used the link to the online survey. Data entered analysis if the following criteria were fulfilled: 1) data completeness (primary endpoints), and 2) either studying or working in the field of social work. Such, $N=727$ participants could be included in the study (82.5\%). The study was approved on February 15, 2021 by the ethics committee of the University of Applied Sciences and Arts (HAWK) containing the a priori defined hypotheses $(1 \mathrm{a} / 1 \mathrm{~b} / 2)$. The survey was completely anonymous; thus, obtaining informed consent was not necessary.

\section{Measurement}

In addition to the primary endpoints (see below), demographic information was recorded (age, gender, field of study/semester or occupation). Furthermore, the survey contained the selfdeveloped, exploratory item "Do you currently feel mentally burdened?" to be answered on a scale from $1=$ "not at all" to 5 = "very much". This item was added to the questionnaire by request of the local ethics committee during the approval process and is not part of a validated scale. It was used as a control item to generally assess the amount of subjective mental burden of participants, and whether subjective burden correlates with our primary outcomes. It has been recently shown that mental burden is highly correlated with symptoms of a stress response (Belz et al., 2021).

\section{Internal and External Locus of Control}

The questionnaire Internal-External-Locus of Control (IE-4, Kovaleva et al., 2014) was used to measure the individually perceived locus of control. Here, two items each measure the scales internal and external locus of control (each subscale score is built by averaging the two scale items). For this purpose, the participants provide ratings of statements such as "I'm my own boss." on a 5 -point Likert scale $(1=$ "not at all true" to $5=$ "completely true") (see Table 1 for formulations of all items). In the context of the present study, the items of IE- 4 were asked twice: once with reference to the "period before the pandemic" (retrospectively), and once with reference to "the current state" (February/March 2021). Apart from this introductory instruction, the items were not modified.

\section{Sense of Coherence}

The Work-Sense-of-Coherence questionnaire (Work-SoC, Bauer et al., 2015) was used to assess sense of coherence. A total of nine items measure work-related sense of coherence (total score: average of all items). Participants give ratings of their work situation on 7-point semantic differentials, each with opposing anchor points (e.g., "manageable" vs "not manageable"; see Table 1 for all formulations). In addition to the total score, three subscales can be formed by averaging the corresponding items: manageability ( 2 items), meaningfulness ( 3 items), and comprehensibility ( 4 items). The items of the Work-SoC were also used twice in the present study, with reference to the "period before the pandemic" (retrospective) and "the current period" (February/March 2021). In addition, the introductory text asked about the "individual study or work situation" to specifically address students as well as professionals. Apart from that, the items remained unchanged.

\section{Statistical Analysis}

SPSS $^{\circledR}$ statistical software (version 26 ) was used for data analysis. Descriptive representation of the variables was accomplished using means $(M)$, mean differences $\left(M_{D i f f}\right)$, standard deviations $(S D)$, frequencies (Freq.), and Pearson correlations $(r)^{1}$.

As primary endpoints of this study, differences between retrospective and current ratings were analyzed for a total of six scales. Hypothesis 1a/1b: 1) internal and 2) external locus of control (IE-4), and Hypothesis 2: sense of coherence (WorkSoC); 3) total score and three subscales: 4) manageability, 5) meaningfulness, and 6) comprehensibility. Six $t$-tests for dependent measures were used to analyze differences between retrospective and current ratings exclusively for the student subsample, along with corresponding effect sizes (Cohen's d: $d_{e m p}$ ).

To analyze possible differences between students and professionals, a general linear model for repeated measures

${ }^{1}$ The four-field correlation coefficient (phi coefficient, $r$ ) was calculated for the correlation of the binary variables "student" vs "professional" and "binary gender" ("male" vs "female"). 
TABLE 1 | Assignment of the translated questionnaire items to the hypotheses (primary endpoints).

Hypotheses 1a/1b: Internal and external locus of control (IE-4)

Answer options

Introductory text: "How do you experience your personal situation in general? [...]"

1a: "I'm my own boss."

1b: "If I work hard, I will succeed."

Likert scale ${ }^{1}$

1c: "Whether at work or in my private life: What I do is mainly determined by others."

$1 d$ : "Fate often gets in the way of my plans."

Hypothesis 2: Sense of coherence (Work-SoC)

Answer options

Introductory text: "How do you experience your personal study/work situation? [...]"

$2 a^{3}$ : "Unmanageable" vs "manageable"

2b: "Pointless" vs "meaningful"

$2 c^{3}$ : "Chaotic" vs "structured"

$2 d^{3}$ : "Uninfluenceable" vs "influenceable"

2e: "Insignificant" vs "significant"

$2 f^{3}$ : "Unclear" vs "clear"

$2 \mathrm{~g}^{3}$ : "Uncontrollable" vs "controllable"

2h: "Not worthwhile" vs "worthwhile"

$2 i^{3}$ : "Unpredictable" vs "predictable"

Notes. All items were answered twice, for (a) the "period before the pandemic", (b) the "current period" (February/March 2021). ' Likert scale (1 = "strongly disagree"; 5 = "strongly agree"), subscales: internal locus of control (1a/1b), external locus of control (1c/1d); ${ }^{2}$ Semantic differential (7-point scale with anchors listed in the table), ${ }^{3}$ inverted in the questionnaire, subscales: manageability (2d/2g), meaningfulness (2b/2e/2h), and comprehensibility (2a/2c/2f/2i).

TABLE 2 | Correlations and descriptive results.

\begin{tabular}{|c|c|c|c|c|c|c|c|c|c|c|}
\hline Variable & 1 & 2 & 3 & 4 & 5 & 6 & 7 & 8 & 9 & $M \pm S D / F r e q$ \\
\hline \multicolumn{11}{|l|}{ Sociodemographic variables } \\
\hline 1. Student vs professional & - & & & & & & & & & s: 403. p: 324 \\
\hline 2. Gender (binary) & -0.031 & - & & & & & & & & $\mathrm{m}: 110 . \mathrm{f}: 613$ \\
\hline 3. Age & $-0.496^{\star \star}$ & -0.065 & - & & & & & & & $31.06 \pm 9.57$ \\
\hline 4. Current mental burden & 0.059 & $0.087^{*}$ & -0.052 & - & & & & & & $3.61 \pm 0.96$ \\
\hline \multicolumn{11}{|l|}{ Locus of control ${ }^{1}$} \\
\hline 5. $\Delta^{1}$ Internal locus of control & -0.020 & -0.057 & 0.035 & $-0.426^{\star *}$ & - & & & & & $-0.72 \pm 0.82$ \\
\hline 6. $\Delta^{1}$ External locus of control & 0.039 & 0.059 & $-0.099^{\star \star}$ & $0.299^{* *}$ & $-0.493^{* *}$ & - & & & & $0.59 \pm 0.88$ \\
\hline \multicolumn{11}{|l|}{ Sense of coherence ${ }^{2}$} \\
\hline 7. $\Delta^{2}$ Manageability & -0.061 & -0.062 & 0.017 & $-0.239^{* *}$ & $0.375^{\star *}$ & $-0.301^{\star \star}$ & - & & & $-1.69 \pm 1.66$ \\
\hline 8. $\Delta^{2}$ Meaningfulness & $-0.240^{\star \star}$ & 0.027 & $0.184^{\star \star}$ & $-0.276^{\star \star}$ & $0.366^{\star *}$ & $-0.209^{\star *}$ & $0.364^{\star \star}$ & - & & $-1.03 \pm 1.50$ \\
\hline 9. $\Delta^{2}$ Comprehensibility & $-0.151^{\star *}$ & -0.065 & $0.090^{\star}$ & $-0.402^{\star \star}$ & $0.447^{\star \star}$ & $-0.318^{\star \star}$ & $0.605^{\star *}$ & $0.429^{* *}$ & - & $-1.69 \pm 1.43$ \\
\hline 10. $\Delta^{2}$ Total score & $-0.196^{\star *}$ & -0.042 & $0.128^{\star \star}$ & $-0.396^{\star \star}$ & $0.498^{\star \star}$ & $-0.343^{\star \star}$ & $0.769^{* \star}$ & $0.745^{\star *}$ & $0.882^{\star \star}$ & $-1.47 \pm 1.21$ \\
\hline
\end{tabular}

Notes. Correlations: ${ }^{*} \mathrm{p}<0.05 ;{ }^{* *} \mathrm{p}<0.01 ; \mathrm{M}=$ mean; $\mathrm{SD}=$ standard deviation; Freq. = frequency; student = 1 vs professional =0; gender (male = 1 , female = 2); mental burden = values from one to 5 ("not at all" to "very much"); $\Delta=$ delta ( $\Delta$ = (current status) - (pre-pandemic status)) of questionnaire scales: ${ }^{1} I E-4$ (values from 1 to 5 , $\mathrm{N}=727$ ); ${ }^{2}$ Work-SoC (value from 1 to 7 , $\mathrm{N}=648)$.

(GLM) was created for each of the six scales. The participants' ratings on the scales ("retrospective" vs "current") were integrated as a twostage within-subject factor. In addition, the occupational situation ("student" vs "professional") was integrated into each GLM as a twostage between-subjects factor. Furthermore, within each GLM, the interaction effect between both factors was tested in order to map possible different trajectories between students and professionals on the individual scales. In order to statistically validate possible interaction effects, testing was conducted between both subgroups by means of two pairwise comparisons each at the retrospective and current time point ( $t$-tests).
Besides the $t$-tests for the student-sample (6 tests), each GLM contained three $F$-tests and two pairwise comparisons $(6 \mathrm{GLM} \times 5$ tests $=30$ tests). Because of $\alpha$-error inflation, all $p$-values reported for the primary outcomes were globally adjusted using the Bonferroni method for the total number of 36 statistical tests. The initial significance level was set at $p<0.05$ (two-tailed). For additional explorative analyses, the $p$-values were not corrected.

As the Work-SoC scale specifically asked for ratings on the "individual study or work situation", only students who were at least in the third semester of a bachelor's degree were included, since otherwise no retrospective statements could be made about 


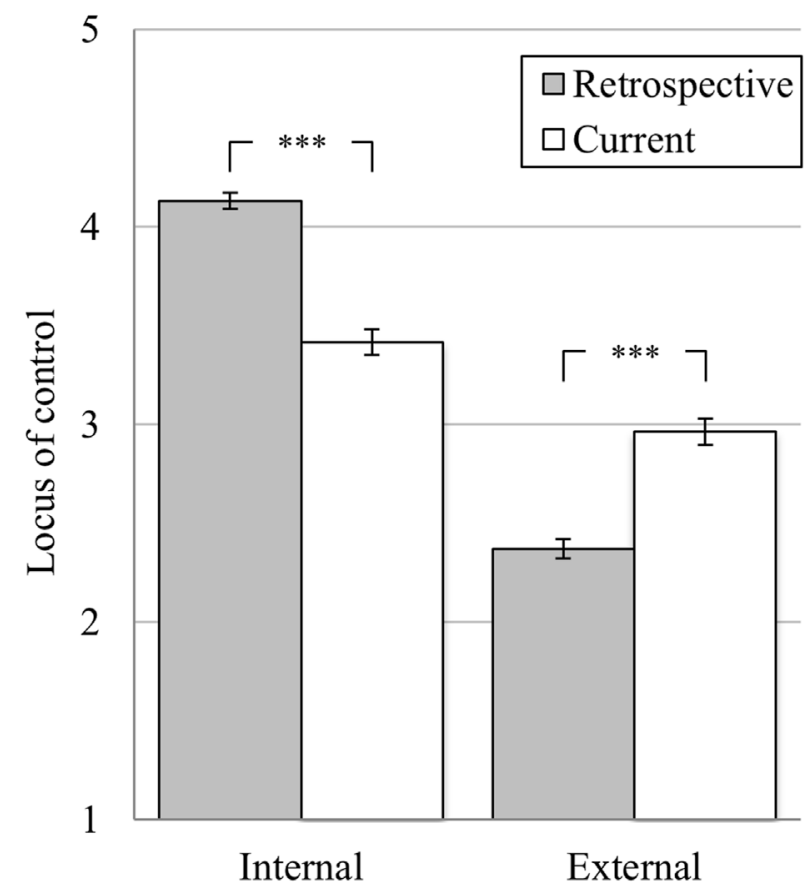

FIGURE 1 | Change in internal and external locus of control. Notes: ${ }^{*} p<$ $0.05 ;{ }^{* \star} p<0.01 ;{ }^{\star \star \star} p<0.001$; means with $95 \%$ confidence intervals $(1=$ "strongly disagree" 5 = "strongly agree"); retrospective = retrospective rating related to a pre-pandemic time-point; current = assessment at the current time point (February/March 2021). $N=727$.

their study situation before the COVID-19 pandemic. In this context, the available total $N$ was reduced from 727 to 648 (see degrees of freedom of the statistical tests).

\section{RESULTS}

\section{Sample and Descriptive Results}

See Table 2 for a summary of descriptive results. Of $N=727$ participants, $n=613(84.3 \%)$ were female and $n=110(15.1 \%)$ were male. In addition, $n=4(0.6 \%)$ reported gender as "diverse." There were $n=403$ (55.4\%) students, and $n=324$ (44.6\%) professionals. The vast majority of students were in the bachelor's program ( $n=368,91.3 \%$; master's: $n=35,8.7 \%)$. The mean age of the total sample was $M=31.06$ years $(S D=9.57)$. On average, students were 9.56 years younger $(M=26.81)$ than professionals $(M=36.37 ; t(724)=15.38, p<0.001)$. Mental burden resulted in ratings of $M=3.61(S D=0.96)$ for the total sample, thus tending to reach 4 = "quite burdened". There was no statistically significant difference between students and professionals in terms of mental burden $(t(722)=1.58, p=0.12$, not significant: $n s)$.

Correlations between the variables are shown in Table 2. The status "student" compared to "professional" correlated with a more pronounced decrease in sense of coherence (Work-SoC) from the pre-pandemic to the current state: Significance was achieved for the Work-SoC total score as well as the subscales meaningfulness and comprehensibility ( $r$ between -0.151 and
-0.240 , all $p<0.001)$. High mental burden also correlated with negative changes in the sense of coherence for all (sub-) scales ( $r$ between -0.239 and -0.402 , all $p<0.001$ ), as well as with decreasing internal locus of control $(r=-0.426, p<0.001)$ and increasing external locus of control $(r=0.299, p<0.001)$.

\section{Locus of Control (Hypothesis 1)}

Students rated their internal locus of control significantly higher at the pre-pandemic $(M=4.15, S D=0.56)$ than at the current time point $\left(M=3.42, S D=0.88 ; t(402)=17.10, p<0.001, d_{\text {emp }}=\right.$ $0.85)$. Thus, the assumption made in Hypothesis 1a, that internal locus of control would decrease in students during the COVID-19 pandemic, is accepted. Also, internal locus of control was rated significantly higher at the pre-pandemic $(M=4.13, S D=0.55)$ than at the current time point $(M=3.42, S D=0.88$, GLM: $F(1,725)=$ 541.13, $p<0.001$, partial $\eta^{2}=0.43$ see Figure 1) by the entire sample. Neither a general difference between professionals and students could be found (between-group effect: $F(1,725)=0.37$, $n s)$ nor different trajectories between the two groups (interaction effect: $F(1,725)=0.29, n s$, all pairwise comparisons $n s)$.

External locus of control was rated significantly lower by students at the pre-pandemic $(M=2.42, S D=0.69)$ compared to the current time point $(M=3.04, S D=0.91 ; t(402)=13.92, p<$ $0.001, d_{\text {emp }}=0.69$ ). The assumption that external locus of control would increase among students during the COVID-19 pandemic (Hypothesis 1b) is accepted. External locus of control was also rated lower at the pre-pandemic $(M=2.37, S D=0.69)$ compared to the current time point $(M=2.96, S D=0.92$, GLM: $F(1,725)=$ $320.05, p<0.001$, partial $\eta^{2}=0.31$ see Figure 1) by the entire sample. Again, neither a different course between students and professionals (interaction effect: $F(1,725)=1.09, n s$, all pairwise comparisons $n s$ ), nor a general difference between both groups (between-group effect: $F(1,725)=7.61, n s)$ could be found.

\section{Sense of Coherence (Hypothesis 2)}

Students rated the sense of coherence (Work-SoC: total score) significantly higher at the pre-pandemic $(M=5.51, S D=0.72)$ than at the current time point $(M=3.80, S D=1.09 ; t(232)=$ 23.13, $p<0.001, d_{\text {emp }}=1.28$ ). Comparable reductions were also found for all three subscales (manageability: $M_{\text {Diff }}=-1.71$, meaningfulness: $M_{\text {Diff }}=-1.39$, comprehensibility $M_{\text {Diff }}=$ -1.90 ; all $p$-values < 0.001). Thus, the assumption made in Hypothesis two that the sense of coherence would decrease in the COVID-19 pandemic for students is accepted for the total score and additionally for all three subscales.

Also, the entire sample rated sense of coherence (Work-SoC: total score) significantly higher at the pre-pandemic $(M=5.48$, $S D=0.74)$ than at the current time point $(M=4.02, S D=1.07$, GLM: $F(1,646)=978.67, p<0.001$, partial $\eta^{2}=0.60$ see Figure 2). Again, reductions from the retrospectively assessed time point compared to the current time point were also found for all three subscales of the Work-SoC questionnaire (manageability: $M_{\text {Diff }}=-1.69$, meaningfulness: $M_{\text {Diff }}=-1.03$, comprehensibility $\left.M_{\text {Diff }}=-1.69\right)$. All reductions in the subscales reached significance (GLM: $F(1,646)$ from 326.37 to 918.61 , all $p$-values $<0.001$, see Figure 2). A significant interaction effect was found for the total score (GLM: $F(1,646)=25.71, p<0.001$, 


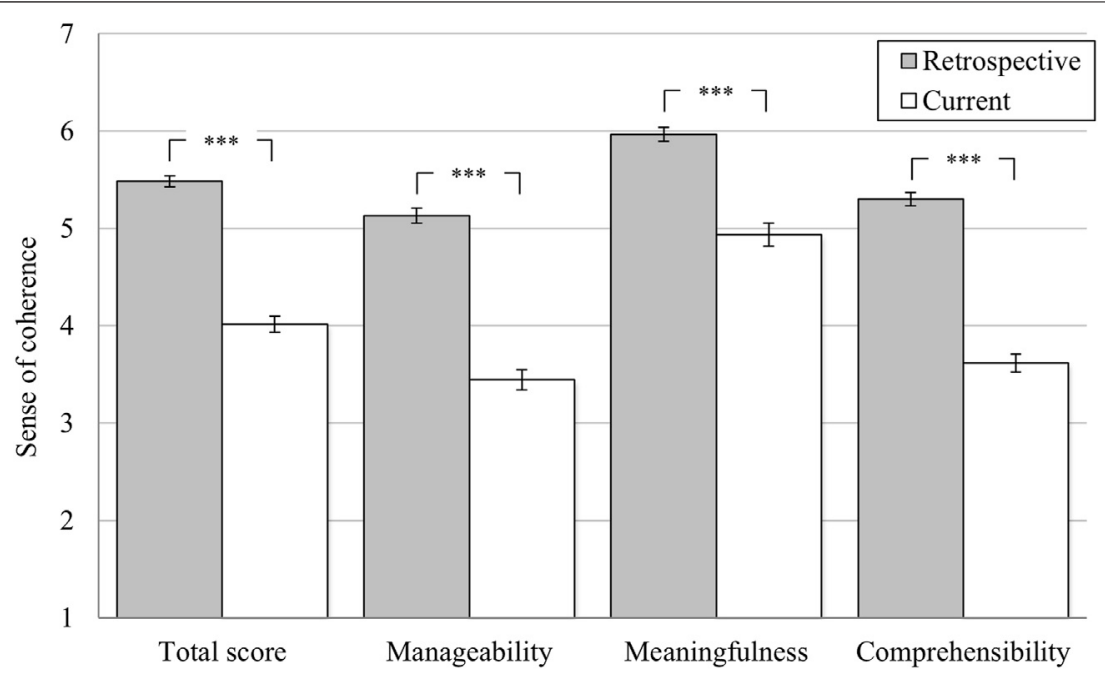

FIGURE 2 | Change in sense of coherence including subscales. Notes: ${ }^{\star} p<0.05 ;{ }^{\star \star} p<0.01 ;{ }^{* \star \star} p<0.001$; means with $95 \%$ confidence intervals $(7-$ point semantic differentials; see Table 1 for item anchors); retrospective = retrospective rating related to a pre-pandemic time-point; current = assessment at the current time-point (February/March 2021). $N=648$.
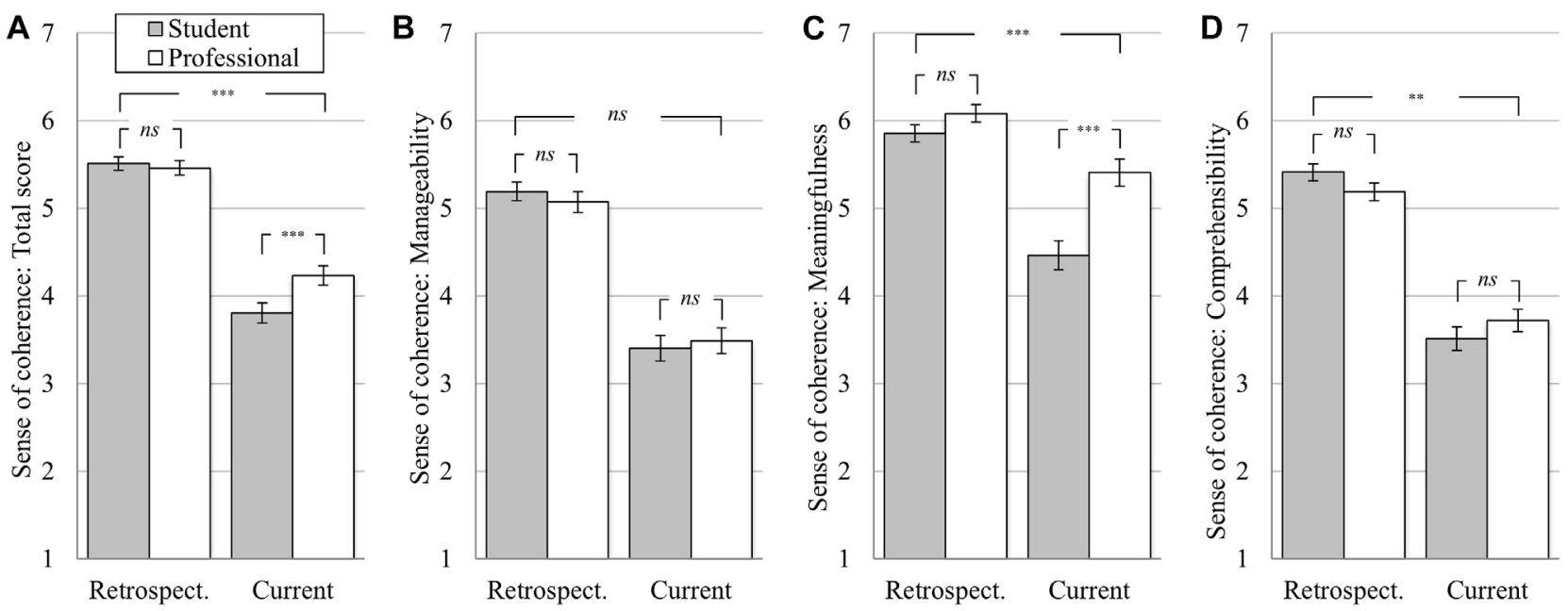

FIGURE 3 | Change in sense of coherence differentiated between students and professionals; (A): total score, (B): manageability, (C): meaningfulness, (D): comprehensibility. Notes: between groups (students vs professionals) and interaction effects; ${ }^{\star} p<0.05 ;{ }^{* *} p<0.01 ;{ }^{* * \star} p<0.001$; means with $95 \%$ confidence intervals (7-point semantic differentials; see Table 1 for item anchors); retrospective = retrospective rating related to a pre-pandemic time-point; current = rating of the current time-point (February/March 2021); students $(n=324)$ vs professionals $(n=324) ; N=648$.

partial $\eta^{2}=0.04$ see Figure 3A). While students and professionals did not differ at the retrospectively assessed pre-pandemic time point $\left(M_{\text {Diff }}=0.05, t(646)=0.88, n s\right)$, students reported a significantly lower sense of coherence than professionals at the current time point $\left(M_{\text {Diff }}=0.42, t(646)=5.16, p<0.001\right)$. For the subscales manageability and comprehensibility, this interaction effect could either not be found, or could not be corroborated by significant pairwise comparisons (see Figure 3B/D). For the subscale meaningfulness, a significant interaction effect was found (GLM: $F(1,646)=39.44, p<0.001$, partial $\eta^{2}=0.06$ see Figure 3C). Again, students and professionals did not differ in their retrospective, pre-pandemic assessment $\left(M_{\text {Diff }}=0.23, \mathrm{t}\right.$ $(646)=3.14, n s)$, but students rated the experienced meaningfulness significantly lower than professionals at the current, peri-lockdown time point $\left(M_{\text {Diff }}=0.94, t(646)=\right.$ 8.18, $p<0.001)$.

\section{DISCUSSION}

The present cross-sectional study investigated whether the COVID-19 pandemic has a negative influence on perceived 
internal locus of control as well as on the sense of coherence in social work students. For this purpose, retrospective ratings about the time before the pandemic were compared with ratings approximately 1 year after the beginning of the pandemic (February/March 2021). To analyze whether these students are specifically vulnerable to experience these changes, we compared ratings of 403 students to those of 324 professionals.

\section{Central Findings of This Study}

As postulated in hypotheses $1 \mathrm{a} / 1 \mathrm{~b}$, the internal locus of control decreased significantly in the population of students during the COVID-19 pandemic, while the external locus of control increased in parallel. No difference between students and professionals could be found; both showed a similar, strong response in the context of the pandemic. Furthermore, an increased mental burden was strongly correlated with a shift from internal to external locus of control. In accordance with previous work, participants interviewed here might have reacted with a strong increase of mental burden due to the experience of powerlessness with regard to their own life organization during the pandemic (Jain and Singh, 2015; Kesavayuth et al., 2020; Sigurvinsdottir et al., 2020; Alat et al., 2021). In other words, their need for control as a central human need (Grawe, 1998) may have been neglected due to pandemic-related restrictions. Hence, a persistently high level of subjective powerlessness could intensify mental health problems and general stress levels in the future (Kinman et al., 2020; Usher et al., 2020). Our results also support prepandemic findings, suggesting a relationship between internal locus of control and mental health (Jain and Singh, 2015; Kesavayuth et al., 2020): Accordingly in this study, internal locus of control was negatively correlated-in contrast to external locus of control-with mental burden.

As postulated in hypothesis 2, the sense of coherence decreased among students during the pandemic. Similarly, a significant drop was found for professionals. One interpretation would be that neither students nor professionals have sufficient coping strategies to deal with pandemic-related challenges and are thus unable to cope adequately with this stressor (Antonovsky, 1979). This may also be accompanied by serious consequences for mental health (Länsimies et al., 2017; Schäfer et al., 2018; Baloran, 2020; Barni et al., 2020; Leung et al., 2021). For sense of coherence, it has to be considered that this concept was originally defined as a developmental construct or a dispositional orientation (Antonovsky, 1979; Hammond and Niedermann, 2010), and would therefore imply to remain essentially unchanged by environmental factors or interventions. In contrast, several empirical studies showed that sense of coherence within a person is not a stable trait per se. Thus, it has been shown to undergo changes (Smith et al., 2003; Feldt et al., 2011), and does not reach stability depending on a certain age (Feldt et al., 2003). With results of a significantly decreasing sense of coherence during the COVID-19 pandemic, the original assumption is challenged. Thus, the present study supports the idea that environmental conditions can change the individual sense of coherence.
It is of particular note that among students both the total score for sense of coherence and, more specifically, the sense of meaningfulness dropped more sharply than among professionals during the pandemic. These findings may be interpreted as specific vulnerability and bear important implications: A connection between subjective meaningfulness and individual work engagement during the COVID-19 pandemic has already been shown for healthcare workers (Liu et al., 2021). In their study, the implementation of a combined organizational intervention (a supportive letter that stressed the subjective meaningfulness and crisis management via counseling sessions) led to increased individual work engagement. One may thus consider that students who perceive their study to be more meaningful and the COVID-19 pandemic as less interfering would also profit from such interventions and increase their engagement. Consequently, subjective study-related meaningfulness should be increased via the promotion of sense-making processes, and may also lead to a reduction of mental burden in students. Fostering of meaning-making processes ("normalization") in light of the pandemic (i.e., recognition that stress reactions are normal given the current situation) represents a promising approach for psychological intervention (Castiglioni and Gaj, 2020): Promoting the understanding of stressful experiences can be considered as an important coping strategy and can substantially contribute to improving sense of coherence. Complementary pandemic-compatible strategies to improve mental health are already available, such as sports psychology interventions (Bertollo et al., 2021), specific pandemic-related training and preparation (Reverté-Villarroya et al., 2021), and the use of interventions such as mindfulness and a reduction of news consumption (Aughterson et al., 2021).

\section{Limitations}

First, in the present cross-sectional study, the assessment of locus of control and sense of coherence was conducted both retrospectively and at a time point approximately 1 year after the beginning of the pandemic, but ultimately it was a post hoc survey. Retrospective assessment is generally more subject to measurement error because it is retrieved from memory and additionally influenced by each participant's personality traits (Ottenstein and Lischetzke, 2020). Accordingly, data must be interpreted with caution. Recently, Belz et al. have shown that a retrospective, questionnaire-based measurement during the COVID-19 pandemic can yield good objectivity, reliability and validity (Belz et al., 2021). In sum, a longitudinal design would minimize this measurement error but was not feasible due to the unpredictability of the pandemic development. Second, the questionnaire was deliberately designed to be short so as not to deter participants from the outset-the mean completion time ( $\min )$ was $M=4.84(S D=1.91)$ with a completion rate of $82.5 \%$. Based on the large sample size acquired, it would have been statistically reasonable to collect more items/scales to gain more insights-however, this would have led to a potentially higher dropout rate at the same time. In this light, we only used a single, self-developed item to assess mental burden of participants ("Do you currently feel mentally burdened?"; 1 = "not at all" to $5=$ 
"very much"). This can be criticized, as-in contrast to the primary outcomes of this study-this item was not derived from an established scale, but simply formulated to record a self-report of mental burden post hoc. The item is thus not theory-driven, which is a clear limitation of this study and why it was only included in the exploratory analysis. In the future, established scales covering multiple facets should be used, even at the cost of a slightly longer questionnaire. Third, although the representativeness of the sample studied here can be considered potentially high due to the large sample size, the survey was conducted online exclusively. This may subject the dataset to inclusion biases that cannot be controlled. It should be noted at this point that due to the increased digitization during the pandemic (e.g., digital teaching, home office) more people have potentially acquired competencies in this area and can thus be widely reached by an online survey. This would in turn be indicative of a good sample representativeness. Fourth, we chose scales to assess locus of control and sense of coherence in this study. Undoubtedly, there are numerous resources which can help to cope with critical life events-like personal traits (e.g., self-efficacy) or energy resources (e.g., money; please see (Hobfoll and Buchwald, 2004) for details). These were neither empirically investigated nor statistically controlled here. It would be worthwhile to consider the relationship between such resources and the main outcomes focused here in future empirical studies.

\section{CONCLUSION}

Social work students and professionals react to the COVID-19 pandemic with increased feelings of powerlessness. Due to the currently unpredictable continuation of the pandemic, the negative effects found here may further escalate. In view of an

\section{REFERENCES}

Alat, P., Das, S. S., Arora, A., and Jha, A. K. (2021). Mental Health during COVID19 Lockdown in India: Role of Psychological Capital and Internal Locus of Control. Curr. Psychol. 12, 1-13. doi:10.1007/s12144-021-01516-x

Antonovsky, A. (1979). Health, Stress, and Coping. San Francisco: Jossey-Bass

Aughterson, H., McKinlay, A. R., Fancourt, D., and Burton, A. (2021). Psychosocial Impact on Frontline Health and Social Care Professionals in the UK during the COVID-19 Pandemic: a Qualitative Interview Study. BMJ Open 11, e047353. doi:10.1136/bmjopen-2020-047353

Baloran, E. T. (2020). Knowledge, Attitudes, Anxiety, and Coping Strategies of Students during COVID-19 Pandemic. J. Loss Trauma 25, 635-642. doi:10.1080/15325024.2020.1769300

Barni, D., Danioni, F., Canzi, E., Ferrari, L., Ranieri, S., Lanz, M., et al. (2020). Facing the COVID-19 Pandemic: The Role of Sense of Coherence. Front. Psychol. 11, 578440. doi:10.3389/fpsyg.2020.578440

Bauer, G. F., Vogt, K., Inauen, A., and Jenny, G. J. (2015). Work-SoC-Entwicklung und Validierung einer Skala zur Erfassung des arbeitsbezogenen Kohärenzgefühls. Z. für Gesundheitspsychologie 23, 20-30. doi:10.1026/0943$8149 / \mathrm{a} 000132$

Bäuerle, A., Steinbach, J., Schweda, A., Beckord, J., Hetkamp, M., Weismüller, B., et al. (2020). Mental Health Burden of the COVID-19 Outbreak in Germany: Predictors of Mental Health Impairment. J. Prim. Care Community Health 11, 2150132720953682. doi:10.1177/2150132720953682 increased vulnerability of students for a deteriorated sense of coherence, longitudinal observations of mental health are urgently needed for this population that has been insufficiently considered so far. Accordingly, the need for appropriate and population-specific intervention strategies would be uncovered.

\section{DATA AVAILABILITY STATEMENT}

The raw data supporting the conclusions of this article will be made available by the authors, without undue reservation.

\section{ETHICS STATEMENT}

The studies involving human participants were reviewed and approved by University of Applied Sciences and Arts (HAWK). Written informed consent for participation was not required for this study in accordance with the national legislation and the institutional requirements.

\section{AUTHOR CONTRIBUTIONS}

Design and conception: MM JS-K, and MB; Data acquisition and statistical analysis: MM MB; Writing: MM CB JS-K, and MB; All authors approved the final version of the manuscript.

\section{ACKNOWLEDGMENTS}

We acknowledge support by the Open Access Publication Funds of the Göttingen University. We would like to thank all respondents for taking the time and effort to participate in our survey.

Belz, M., Hessmann, P., Vogelgsang, J., Schmidt, U., Ruhleder, M., SignerskiKrieger, J., et al. (2021). Evolution of Psychosocial burden and Psychiatric Symptoms in Patients with Psychiatric Disorders during the Covid-19 Pandemic. Eur. Arch. Psychiatry Clin. Neurosci. 3, 1-12. doi:10.1007/s00406021-01268-6

Bertollo, M., Forzini, F., Biondi, S., Di Liborio, M., Vaccaro, M. G., Georgiadis, E., et al. (2021). How Does a Sport Psychological Intervention Help Professional Cyclists to Cope with Their Mental Health during the COVID-19 Lockdown? Front. Psychol. 12, 607152. doi:10.3389/fpsyg.2021.607152

Castiglioni, M., and Gaj, N. (2020). Fostering the Reconstruction of Meaning Among the General Population during the COVID-19 Pandemic. Front. Psychol. 11, 567419. doi:10.3389/fpsyg.2020.567419

Chaturvedi, K., Vishwakarma, D. K., and Singh, N. (2021). COVID-19 and its Impact on Education, Social Life and Mental Health of Students: A Survey. Child. Youth Serv. Rev. 121, 105866. doi:10.1016/j.childyouth.2020.105866

del-Pino-Casado, R., Espinosa-Medina, A., López-Martínez, C., and Orgeta, V. (2019). Sense of Coherence, burden and Mental Health in Caregiving: A Systematic Review and Meta-Analysis. J. Affect Disord. 242, 14-21. doi:10.1016/j.jad.2018.08.002

Dodd, R. H., Dadaczynski, K., Okan, O., McCaffery, K. J., and Pickles, K. (2021). Psychological Wellbeing and Academic Experience of University Students in Australia during COVID-19. Int. J. Environ. Res. Public Health 18, 866. doi:10.3390/ijerph18030866

Dost, S., Hossain, A., Shehab, M., Abdelwahed, A., and Al-Nusair, L. (2020). Perceptions of Medical Students towards Online Teaching during the COVID- 
19 Pandemic: a National Cross-Sectional Survey of 2721 UK Medical Students. BMJ Open 10, e042378. doi:10.1136/bmjopen-2020-042378

Elmer, T., Mepham, K., and Stadtfeld, C. (2020). Students under Lockdown: Comparisons of Students' Social Networks and Mental Health before and during the COVID-19 Crisis in Switzerland. PLoS ONE 15, e0236337. doi:10.1371/journal.pone.0236337

Federal Government Germany (2021). Bund und Länder beschließen stufenweise Lockerungen. Bundesregierung. Available at: https://www.bundesregierung.de/ breg-de/themen/coronavirus/bund-laender-beschluss-1872126 [Accessed March 23, 2021].

Feldt, T., Leskinen, E., Koskenvuo, M., Suominen, S., Vahtera, J., and Kivimäki, M. (2011). Development of Sense of Coherence in Adulthood: a Person-Centered Approach. The Population-Based HeSSup Cohort Study. Qual. Life Res. 20, 69-79. doi:10.1007/s11136-010-9720-7

Feldt, T., Leskinen, E., Kinnunen, U., and Ruoppila, I. (2003). The Stability of Sense of Coherence: Comparing Two Age Groups in a 5-year Follow-Up Study. Personal. Individual Differences 35, 1151-1165. doi:10.1016/S0191-8869(02)00325-2

Gómez-Salgado, J., Domínguez-Salas, S., Romero-Martín, M., Ortega-Moreno, M., García-Iglesias, J. J., and Ruiz-Frutos, C. (2020). Sense of Coherence and Psychological Distress Among Healthcare Workers during the COVID-19 Pandemic in Spain. Sustainability 12, 6855. doi:10.3390/su12176855

Grawe, K. (1998). Psychologische Therapie. Verlag für Psychologie. Goettingen, Germany: Hogrefe, 1943-2005.

Hammond, A., and Niedermann, K. (2010). "Patient Education and Self Management," in "Chapter 6 - Patient Education and Self Management," in Rheumatology. Editors K. Dziedzic and A. Hammond (Edinburgh: Churchill Livingstone), 77-97. doi:10.1016/B978-0-443-06934-5.00006-1

Hobfoll, S. E., and Buchwald, P. (2004). "“'Die Theorie der Ressourcenerhaltung und das multiaxiale Copingmodell - eine innovative Stresstheorie," in in Stress gemeinsam bewältigen - Ressourcenmanagement und multi-axiales Coping. Editors P. Buchwald, C. Schwarzer, and S. E. Hobfoll (Göttingen: Hogrefe, 11-26.

Hobfoll, S. E. (2001). The Influence of Culture, Community, and the Nested-Self in the Stress Process: Advancing Conservation of Resources Theory. Appl. Psychol. 50, 337-421. doi:10.1111/1464-0597.00062

Jain, M., and Singh, S. (2015). Locus of Control and its Relationship with Mental Health and Adjustment Among Adolescent Females. J. Ment. Health Hum Behav 20, 16. doi:10.4103/0971-8990.164803

Jung, S., Kneer, J., and Krüger, T. H. C. (2020). Mental Health, Sense of Coherence, and Interpersonal Violence during the COVID-19 Pandemic Lockdown in Germany. J. Clin. Med. 9, 3708. doi:10.3390/jcm9113708

Kesavayuth, D., Poyago-Theotoky, J., Tran, D. B., and Zikos, V. (2020). Locus of Control, Health and Healthcare Utilization. Econ. Model. 86, 227-238. doi:10.1016/j.econmod.2019.06.014

Kesner, L., and Horáček, J. (2020). Three Challenges that the COVID-19 Pandemic Represents for Psychiatry. Br. J. Psychiatry 217, 475-476. doi:10.1192/bjp.2020.106

Kinman, G., Teoh, K., and Harriss, A. (2020). Supporting the Well-Being of Healthcare Workers during and after COVID-19. Occup. Med. (Lond) 70, 294-296. doi:10.1093/occmed/kqaa096

Kovaleva, A., Beierlein, C., Kemper, C. J., and Rammstedt, B. (2014). "InternaleExternale-Kontrollüberzeugung-4 (IE-4)," in usammenstellung sozialwissenschaftlicher Items und Skalen (ZIS). doi:10.6102/ZIS184

Kramer, V., Papazova, I., Thoma, A., Kunz, M., Falkai, P., Schneider-Axmann, T., et al. (2021). Subjective burden and Perspectives of German Healthcare Workers during the COVID-19 Pandemic. Eur. Arch. Psychiatry Clin. Neurosci. 271, 271-281. doi:10.1007/s00406-020-01183-2

Kurtović, A., Vuković, I., and Gajić, M. (2018). The Effect of Locus of Control on University Students' Mental Health: Possible Mediation through Self-Esteem and Coping. J. Psychol. 152, 341-357. doi:10.1080/00223980.2018.1463962

Länsimies, H., Pietilä, A. M., Hietasola-Husu, S., and Kangasniemi, M. (2017). A Systematic Review of Adolescents' Sense of Coherence and Health. Scand. J. Caring Sci. 31, 651-661. doi:10.1111/scs.12402

Leung, A. Y. M., Parial, L. L., Tolabing, M. C., Sim, T., Mo, P., Okan, O., et al. (2021). Sense of Coherence Mediates the Relationship between Digital Health Literacy and Anxiety about the Future in Aging Population during the COVID-19 Pandemic: a Path Analysis. Aging Ment. Health 0, 1-10. doi:10.1080/13607863.2020.1870206

Liu, D., Chen, Y., and Li, N. (2021). Tackling the Negative Impact of COVID-19 on Work Engagement and Taking Charge: A Multi-Study Investigation of Frontline Health Workers. J. Appl. Psychol. 106, 185-198. doi:10.1037/apl0000866
McGinty, E. E., Presskreischer, R., Han, H., and Barry, C. L. (2020). Psychological Distress and Loneliness Reported by US Adults in 2018 and April 2020. JAMA 324, 93-94. doi:10.1001/jama.2020.9740

Meda, N., Pardini, S., Slongo, I., Bodini, L., Zordan, M. A., Rigobello, P., et al. (2021). Students' Mental Health Problems before, during, and after COVID-19 Lockdown in Italy. J. Psychiatr. Res. 134, 69-77. doi:10.1016/j.jpsychires.2020.12.045

Ottenstein, C., and Lischetzke, T. (2020). Recall Bias in Emotional Intensity Ratings: Investigating Person-Level and Event-Level Predictors. Motiv. Emot. 44, 464-473. doi:10.1007/s11031-019-09796-4

Reverté-Villarroya, S., Ortega, L., Lavedán, A., Masot, O., Burjalés-Martí, M. D., Ballester-Ferrando, D., et al. (2021). The Influence of COVID-19 on the Mental Health of Final-year Nursing Students: Comparing the Situation before and during the Pandemic. Int. J. Ment. Health Nurs 30, 694-702. inm. doi:10.1111/ inm. 12827

Robillard, R., Daros, A. R., Phillips, J. L., Porteous, M., Saad, M., Pennestri, M.H., et al. (2021). Emerging New Psychiatric Symptoms and the Worsening of Pre-existing Mental Disorders during the COVID-19 Pandemic: A Canadian Multisite Study: Nouveaux symptômes psychiatriques émergents et détérioration des troubles mentaux préexistants durant la pandémie de la COVID-19: une étude canadienne multisite. Can. J. Psychiatry 706743720986786, 070674372098678. doi:10.1177/ 0706743720986786

Rossi, R., Socci, V., Talevi, D., Mensi, S., Niolu, C., Pacitti, F., et al. (2020). COVID19 Pandemic and Lockdown Measures Impact on Mental Health Among the General Population in Italy. Front. Psychiatry 11, 790. doi:10.3389/ fpsyt.2020.00790

Rotter, J. B. (1966). Generalized Expectancies for Internal versus External Control of Reinforcement. Psychol. Monogr. 80, 1-28. doi:10.1037/h0092976

Ruiz-Frutos, C., Ortega-Moreno, M., Allande-Cussó, R., Ayuso-Murillo, D., Domínguez-Salas, S., and Gómez-Salgado, J. (2021). Sense of Coherence, Engagement, and Work Environment as Precursors of Psychological Distress Among Non-health Workers during the COVID-19 Pandemic in Spain. Saf. Sci. 133, 105033. doi:10.1016/j.ssci.2020.105033

Schäfer, S. K., Lass-Hennemann, J., Groesdonk, H., Volk, T., Bomberg, H., Staginnus, M., et al. (2018). Mental Health in Anesthesiology and ICU Staff: Sense of Coherence Matters. Front. Psychiatry 9, 440. doi:10.3389/ fpsyt.2018.00440

Schäfer, S. K., Sopp, M. R., Schanz, C. G., Staginnus, M., Göritz, A. S., and Michael, T. (2020). Impact of COVID-19 on Public Mental Health and the Buffering Effect of a Sense of Coherence. Psychother Psychosom 89, 386-392. doi:10.1159/ 000510752

Sidola, S., Saini, S., and Kang, T. K. (2020). Locus of Control and its Relationship with Mental Health Among College Students. Int.J.Curr.Microbiol.App.Sci 9 , 210-220. doi:10.20546/ijcmas.2020.901.024

Sigurvinsdottir, R., Thorisdottir, I. E., and Gylfason, H. F. (2020). The Impact of COVID-19 on Mental Health: The Role of Locus on Control and Internet Use. Int. J. Environ. Res. Public Health 17, 6985. doi:10.3390/ ijerph 17196985

Smith, P. M., Breslin, F. C., and Beaton, D. E. (2003). Questioning the Stability of Sense of Coherence-Tthe Impact of Socio-Economic Status and Working Conditions in the Canadian Population. Soc. Psychiatry Psychiatr. Epidemiol. 38, 475-484. doi:10.1007/s00127-003-0654-z

Son, C., Hegde, S., Smith, A., Wang, X., and Sasangohar, F. (2020). Effects of COVID-19 on College Students' Mental Health in the United States: Interview Survey Study. J. Med. Internet Res. 22, e21279. doi:10.2196/21279

Suar, D., Das, S. S., and Alat, P. (2015). Bereavement, Postdisaster Trauma, and Behavioral Changes in Tsunami Survivors. Death Stud. 39, 226-233. doi:10.1080/07481187.2014.979957

Tan, B. Y. Q., Chew, N. W. S., Lee, G. K. H., Jing, M., Goh, Y., Yeo, L. L. L., et al. (2020). Psychological Impact of the COVID-19 Pandemic on Health Care Workers in Singapore. Ann. Intern. Med. 173, 317-320. doi:10.7326/M201083

Usher, K., Durkin, J., and Bhullar, N. (2020). The COVID-19 Pandemic and Mental Health Impacts. Int. J. Ment. Health Nurs. 29, 315-318. doi:10.1111/inm.12726 Van Rheenen, T. E., Meyer, D., Neill, E., Phillipou, A., Tan, E. J., Toh, W. L., et al. (2020). Mental Health Status of Individuals with a Mood-Disorder during the COVID-19 Pandemic in Australia: Initial Results from the COLLATE Project. J. Affect Disord. 275, 69-77. doi:10.1016/j.jad.2020.06.037 
Wang, C., Pan, R., Wan, X., Tan, Y., Xu, L., McIntyre, R. S., et al. (2020a). A Longitudinal Study on the Mental Health of General Population during the COVID-19 Epidemic in China. Brain Behav. Immun. 87, 40-48. doi:10.1016/ j.bbi.2020.04.028

Wang, X., Hegde, S., Son, C., Keller, B., Smith, A., and Sasangohar, F. (2020b). Investigating Mental Health of US College Students during the COVID-19 Pandemic: Cross-Sectional Survey Study. J. Med. Internet Res. 22, e22817. doi:10.2196/22817

Conflict of Interest: The authors declare that the research was conducted in the absence of any commercial or financial relationships that could be construed as a potential conflict of interest.
Publisher's Note: All claims expressed in this article are solely those of the authors and do not necessarily represent those of their affiliated organizations, or those of the publisher, the editors and the reviewers. Any product that may be evaluated in this article, or claim that may be made by its manufacturer, is not guaranteed or endorsed by the publisher.

Copyright (๑) 2021 Misamer, Signerski-Krieger, Bartels and Belz. This is an open-access article distributed under the terms of the Creative Commons Attribution License (CC BY).

The use, distribution or reproduction in other forums is permitted, provided the original author(s) and the copyright owner(s) are credited and that the original publication in this journal is cited, in accordance with accepted academic practice. No use, distribution or reproduction is permitted which does not comply with these terms. 